\title{
Modeling of photovoltaic system with maximum power point tracking control by neural networks
}

\author{
Farid Saadaoui ${ }^{1}$, Khaled. Mammar ${ }^{2}$, Abdaldjabar. Hazzab ${ }^{3}$ \\ ${ }^{1,3}$ Research Laboratory Control Analysis and Optimization of Systems Electro-Energetic (CAOSEE), \\ University of Tahri Mohamed, Algeria \\ ${ }^{2}$ Department of Electrical Engineering, University of Tahri Mohamed, Algeria
}

\begin{tabular}{l}
\hline \hline Article Info \\
\hline Article history: \\
Received Dec 27, 2018 \\
Revised Mar 1, 2019 \\
Accepted Apr 3, 2019
\end{tabular}

Keywords:

$\mathrm{PV}$

GPV

MPPT

ANN

$\mathrm{P} \& \mathrm{O}$

\begin{abstract}
This paper presented the study, development and implementation of the maximum power point of a photovoltaic energy generator adapted by elevator converter and controlled by a maximum power point command. In order to improve photovoltaic system performance and to force the photovoltaic generator to operate at its maximum power point, the idea of the context of this paper deals with the exploitation of the technique of the artificial intelligence mechanism (neural network) certainly based on the three parts of the photovoltaic system (photovoltaic module inputs (temperature and solar radiation), photovoltaic module and control (MPPT)) that have been adopted within a simulation time of 24 hours. In addition, to reach the optimal operating point regardless of variations in climatic conditions, the use of a neuron network based disturbance and observation algorithm $(\mathrm{P} \& \mathrm{O})$ is put into service of the system given its reliability, its simplicity and view that at any time it can follow the desired maximum power. The entire system is implemented in the Matlab/Simulink environment where simulation results obtained are very promising and have shown the effectiveness and speed of neural technology that still require a learning base so to improve the performance of photovoltaic systems and exploit them in energy production, as well as this technique has proved that these results are much better in terms (of its very great precision and speed of computation) than those of the controller based on the conventional MPPT method P \& O.
\end{abstract}

Copyright (c) 2019 Institute of Advanced Engineering and Science. All rights reserved.

\section{Corresponding Author:}

Farid Saadaoui,

Departement of Electrical Engineering,

Tahri Mohamed University,

Bp417 Bechar, Algeria.

Email: fsaadaoui1969@gmail.com

\section{INTRODUCTION}

The world's energy demands and needs are constantly growing, and enormous research has been conducted and exploited on the production and consumption of renewable energy, which has the advantage of being flexible, reliable and non-polluting. The constraint imposed is to use an economical and efficient source of energy to minimize fuel supply problems to protect our environment.

Renewable energy sources play an important role in electricity generation. Solar energy is one of these important alternative sources that depends on the atmosphere, temperature and solar radiation that varies considerably during the day and its optimal use requires taking into account different types of charges such as (batteries, lighting systems, lamps, and motors). In order to permanently get the maximum power from this photovoltaic (PV) that must run at their maximum power point tracking (MPPT) despite climate change. For this reason a better establishment and exploitation of photovoltaic systems surely lead to a good 
important production of solar energy which takes into account the problem of degradation of the power supplied by the solar generator due to the variation of the radiation which can reach $50 \%$ [1].

To maximize the electricity production of photovoltaic panels in an optimal way we use a Boost converter which is able to give a maximum power under optimal conditions whatever are the variations of the radiation and independently of the meteorological conditions of the variation of the load.

The main factors that influence the efficiency of the process of collecting this solar radiation are the efficiency of the solar cells, the intensity of the source radiation and the storage techniques. The efficiency of these solar cells is limited by the materials used in the manufacture of cells. It is particularly difficult to significantly improve the cell's performance, which limits the efficiency of the overall collection process [1], [2].

In this study we are interested in applying the neural networks in three independent parts of the photovoltaic (PV) chain as shown in Figure 1, (incoming radiation and temperature, PV panel and maximum power point tracking (MPPT) control), in order to study the influence of artificial intelligence on this behavior.

\section{PHOTOVOLTAIC GENERATOR MODELING}

\subsection{Photovoltaic cell modeling}

The photovoltaic panel is composed of several silicon cells connected in series and in parallel. They absorb solar energy and transform them into electrical current. This transformation is done by converters in order to regulate the voltage and current output of this solar cell Figure 2.

$$
\begin{aligned}
& I_{P h}=I_{D}+I+I_{R p} \\
& I_{D}=I_{S}\left[\exp \left(\frac{q\left(V+I R_{S}\right)}{n K T}\right)-1\right]
\end{aligned}
$$

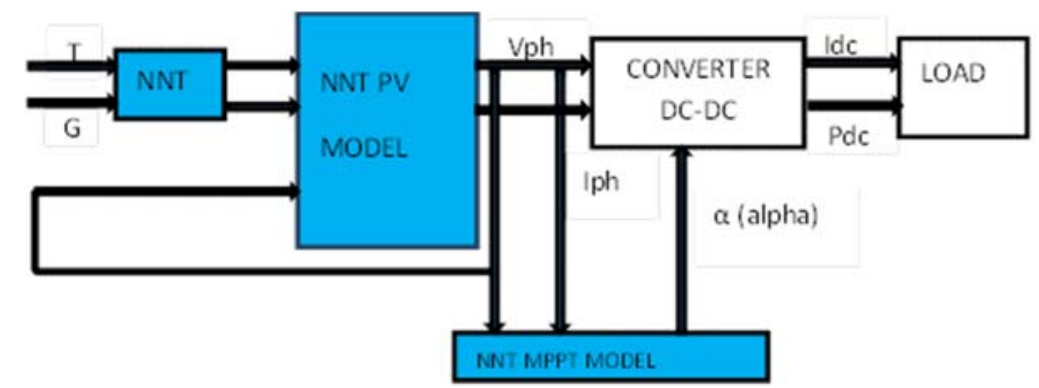

Figure 1. Overview of a maximum power point tracking, MPPT-controlled photovoltaic, PV generator system with neural network ANN

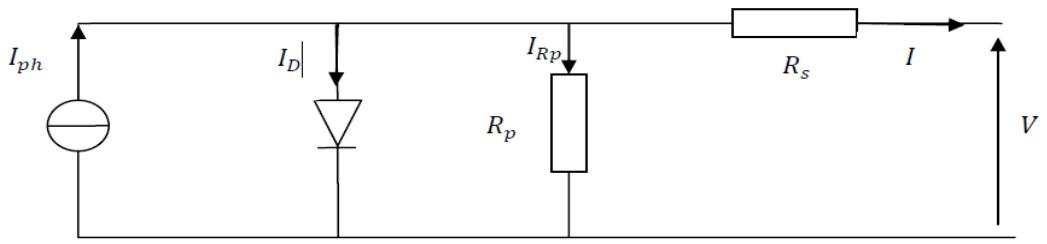

Figure 2. Equivalent circuit of solar cell

$$
I_{s}=K_{1} T^{3} \exp \left(\frac{-E_{g}}{K T}\right)
$$


Is: is the saturation current of the diode

$V_{t}=\frac{K T}{q}$

$V_{t}:$ is the thermic voltage at temperature $\mathrm{T}$

$I_{R p}=\frac{V+I R_{S}}{R_{P}}$

from equation (1) we obtain the expression of characteristic I-V of the chosen model

$$
\begin{aligned}
& I=I_{P h}-I_{s}\left[\exp \left(\frac{V+I R_{S}}{n V_{t}}\right)-1\right]-\frac{V+I R_{s}}{R p} \\
& I_{P h}=\left(I_{s c}+K_{i} d T\right) \frac{G}{G_{n}}
\end{aligned}
$$

$G$ : Solar radiation and $G_{n}$ : Nominal solar radiation

$$
I_{s}=\frac{I_{S C}+K_{i} d T}{\exp \left(\frac{V_{0 C}+K_{V} d T}{V_{t} a}\right)-1}
$$

$a$ : diode ideality factor

$$
I=N_{P P} I_{P h}-N_{P P} I_{S}\left[\exp \left(\frac{V+\left(R_{S} N_{S S} / N_{P P}\right) I}{V_{t} a}\right)-1\right]-\frac{V+\left(R_{S} N_{S S} / N_{P P}\right) I}{R_{P} N_{S S} / N_{P P}}
$$

$N_{P P}:$ is the number of photovoltaic modules in parallel $=1$

$N_{S S}:$ is the number of photovoltaic modules in series $=36$

The choice of a PV model generally depends on the use that we want to make and the information available to determine the parameters. Each model must be based on classical principles [3] Table 1. In order to improve the electrical management of PV system, it is essential to model and analyse these specific intrinsic characteristics [4].

Table 1. The electrical characteristics of photovoltaic module

\begin{tabular}{cc}
\hline Parameters & Values \\
\hline Gr: Solar radiation reference & $1000\left(\mathrm{~W} / \mathrm{m}^{2}\right)$ \\
Rs: Equivalent series resistance of the resistive contacts & $0.5 \mathrm{Ohms}$ \\
Rsh: Shunt resistance representing the leaking currents & $500 \mathrm{Ohms}$ \\
q: Electron charge & $1.602^{*} 10^{\wedge}-19 \mathrm{C}$ \\
$\mathrm{K}:$ Boltzmann constant & $1.38^{*} 10^{\wedge}-23 \mathrm{~J} /{ }^{\circ} \mathrm{K}$ \\
$\mathrm{T}:$ is the effective temperature of the cell & ${ }^{\circ} \mathrm{K}$ \\
Tinit: Initial temperature of the PV Cell & $298^{\circ} \mathrm{K}$ \\
Isc: Short-circuit current & $3.33 \mathrm{~A}$ \\
Voc : Initial open-circuit voltage & $21.3 \mathrm{~V}$ \\
$\mathrm{Ki}:$ Temperature versus current coefficient & $0.0025 \mathrm{~A} /{ }^{\circ} \mathrm{C}$ \\
Eg : Gap energy silicium & $1,12 \mathrm{eV}$ \\
\hline
\end{tabular}

Modeling of photovoltaic system with maximum power point tracking control by ... (Farid Saadaoui) 


\subsection{Artificial neural network model}

The artificial neural network (ANN) is a mathematical computation concept that belongs to the family of methods of artificial intelligence, whose schematic design resembles the neurons of the human brain based on logical reasoning. Its structure is composed of three layers as shown in details below choice in Figure 3.

- Input layer: composed of three neurons that transmit the value of the input signal that corresponds to the variable output voltage of the photovoltaic panel to the next layer.

- the hidden layer: which is composed of ten neurons with defined activation functions.

- the output layer: composed of one neuron, the output of neuron which is a 0 or 1 logic variable.

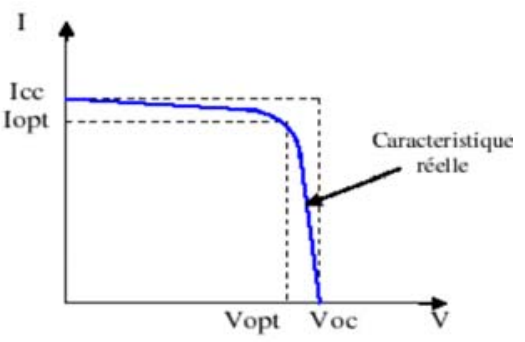

Figure 3. Characteristic of the PV cell

The number of nodes in each layer varies and depends on the user. The ANN input variables or signals are the PV generator input parameters such as temperature and solar radiation, while the output signal is the maximum identified power.

The choice of ANN is made according to: the type of neurons, the number of neuron layers and the study methods, their advantages in broadband used in industry is the storage of an enormous mass of information and the direct storage in real time of this information, allowing to make logical decisions, efficiency to solve problems of non-linearities. The ANN is noted for sensitivity to noise. Generally the neuron output will be one or more reference signal(s) [5]. The ANN performs three calculation operations on its inputs [6]:

- The ponderation (weight): the multiplication of any input by a specific factor (which is the connection weight).

- The sum: according to all inputs weight.

- The activation function ( $\mathrm{f}$ ).

The architectural synoptic of the proposed neural network (3-10-2) consists of an input layer with 3 inputs (solar radiation $\mathrm{G}$, temperature $\mathrm{T}$ and voltage $\mathrm{V}$ ), a hidden layer of 10 neurons and an output layer with 2 output (current I and voltage V) Figure 22. The models used in MATLAB for building neurons are different, using the hyperbolic tangent sigmoid transfer function in the hidden layer "tansig" and the transfer function "purelin" for the output layer. The hidden layer transfer function is a sigmoid function defined as follow:

$$
f(u)=\frac{1}{1+e^{-(d . u)}}
$$

Where $\mathrm{d}:$ is the slope parameter.

The entry of the hidden layer is expressed by the following relationship:

$$
u=\sum_{j=1}^{n}\left(w_{i j} x_{i}+b_{i}\right)
$$

Where $\mathrm{W}_{\mathrm{ij}}$ is the weight of the $\mathrm{jth}$ input $\mathrm{X}_{\mathrm{j}}$ to the $\mathrm{i}_{\text {th }}$ neuron in the hidden layer and bi is the bias. If the function in the output layer is linear then the neural network set is expressed by the following relationship:

Int J Pow Elec \& Dri Syst, Vol. 10, No. 3, Sep 2019 : 1575 - 1591 


$$
y_{k} u=\sum_{j=1}^{N}\left(w_{i j}^{o} u_{i}+b_{i}\right)=u=\sum_{j=1}^{N} w_{i j}^{o} f\left(\sum_{j=1}^{N}\left(w_{i j} x_{i}+b_{i}\right)\right)
$$

$y_{k}$ : is the output signal of the kth output neurons and $w_{k i}^{o}$ is the weight of the ith output $u_{i}$ to the kieme neurons in the output layer.

The bias and weighting values of the neuron are determined as a function of the usage algorithm. $\mathrm{W}_{\mathrm{ij}}$ is the weight of the connection between neurons $\mathrm{i}$ and $\mathrm{j}$ and each neuron is connected to the set of neurons of the next layer by these weights which are real numbers. The constutution and type of algorithms of the ANN automatically affect the MPPT. The contribution of the neural network is therefore used to approximate and evaluate the maximum power of the PV module and to drive the Boost (DC-DC) power converter to operate close to the MPPT, despite the different operating conditions that change the characteristics of a photovoltaic generator over time and that impose the formation of the neural network in a periodic manner to result in a preferred MPPT.

The boost converter is also known as a step-up converter. It is generally used in converting a low input voltage to a high output voltage [7]. The MPPT control allows you to be at any time from the sun to the maximum power of our PV system. To simulate the maximum power, we first connected our PV system directly to the load, and then we connected the boost converter controlled by the MPPT between the load and the PV system [7].

\section{CHARACTERISTICS ANALYSIS OF A PHOTOVOLTAIC GENERATOR}

\subsection{Characteristic $I-V$ \& $P-V$}

The current Iph produced by the cell is directly proportional to the solar radiation $\mathrm{G}$, with a small voltage variation and the open circuit voltage will decrease only slightly with radiation. Thus, the optimal power of the cell is practically proportional to the radiation and the maximum power points are approximately at the same voltage [8].

\subsubsection{Influence of the température on the $I-V \& P-V$ characteristic}

Figure 4 and Figure 5 shows the characteristics of the I-V and P-V of the photovoltaic module with a maximum selected power of approximately $55 \mathrm{~W}$, in a temperature variation from $\left(10^{\circ} \mathrm{C}\right.$ to $\left.60^{\circ} \mathrm{C}\right)$. This temperature increase has a direct influence on the behaviour of the $\mathrm{PV}$, it causes a reduction in the open circuit voltage of about $2 \mathrm{mV}$ per degree with a negligible influence on the photo-current considered. In the same way, the power produced decreases slightly following the voltage decline, which directly reflects the decrease in the maximum available power, therefore, on the efficiency of the cell. Consequently, the undesirable effect of temperature on a photovoltaic panel can damage the system and shorten its life, especially in the hottest areas.

\subsubsection{Influence of the radiation on the $I-V \& P-V$ caractéristic}

The influence of solar radiation on characteristic I-V is considerable, especially on the photocurrent and weak on the voltage:

$$
I_{p h} \approx I_{c} \approx \propto A G
$$

$\alpha$ : is the light absorption coefficient and A: is the active surface of the cell.

The characteristic shows that the efficiency depends on the radiation:

$$
\eta=\frac{P_{\max }}{P_{i}}=\frac{V_{\max } \cdot I_{\max }}{\alpha G A}
$$

This factor is variable throughout the day and cannot be increased, therefore on the power-voltage characteristic, depending on the relationship (13) and for better PV performance resolution, the solution is to choose a large area of high radiation to expose the solar panels [9].

Figures 4 and 5 show the variation of the I-V and P-V characteristics of the PV module at different temperatures which range from $0{ }^{\circ} \mathrm{C}$ to $60^{\circ} \mathrm{C}$ when the radiation is kept constant at $1000 \mathrm{~W} / \mathrm{m} 2$. As the temperature increases, the short circuit current increases, but the open-circuit voltage decreases. Thus, the output power of the cell is also decreased.

Modeling of photovoltaic system with maximum power point tracking control by ... (Farid Saadaoui) 
Figures 6 and 7 show the variation of the $\mathrm{I}-\mathrm{V}$ and $\mathrm{P}-\mathrm{V}$ characteristics of the PV module at a constant ambient temperature $\mathrm{T}=25^{\circ} \mathrm{C}$, by modifying the radiation values from $250 \mathrm{~W} / \mathrm{m} 2$ to $1000 \mathrm{~W} / \mathrm{m} 2$. If the radiation increases the maximum power is higher and also the current also increases.

Finally we can easily say from these figures that the operating point of the maximum power generated is due to the increase of the solar radiation which causes an increase of the current due to the circuit of cut is of course the voltage in the open circuit remains almost constant.

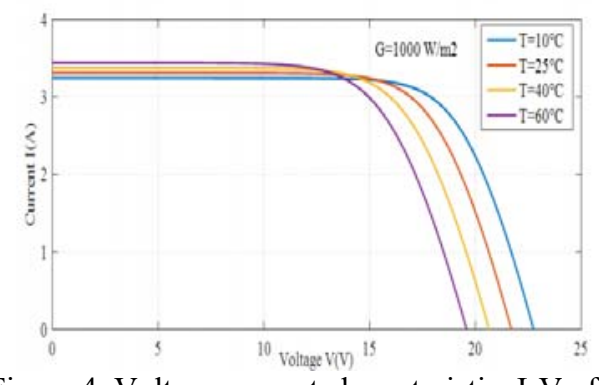

Figure 4. Voltage current characteristic, I-V of a photovoltaic module, PV for different temperatures and constant radiation

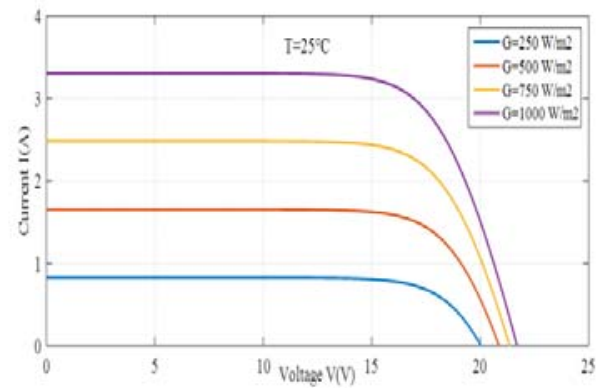

Figure 6. Voltage current characteristic I-V of a photovoltaic module $\mathrm{PV}$ for different radiations and constant temperature

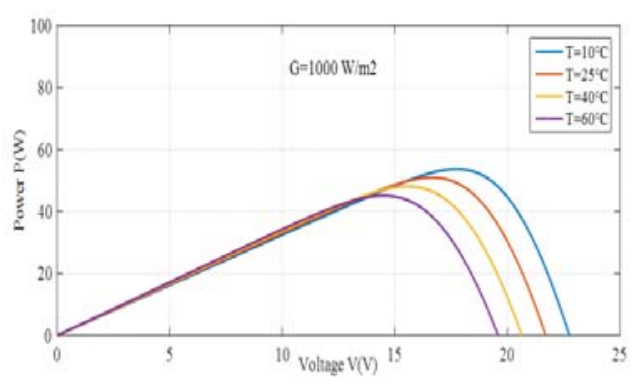

Figure 5. Voltage power characteristic, P-V of a photovoltaic module, PV for different temperatures and constant radiation

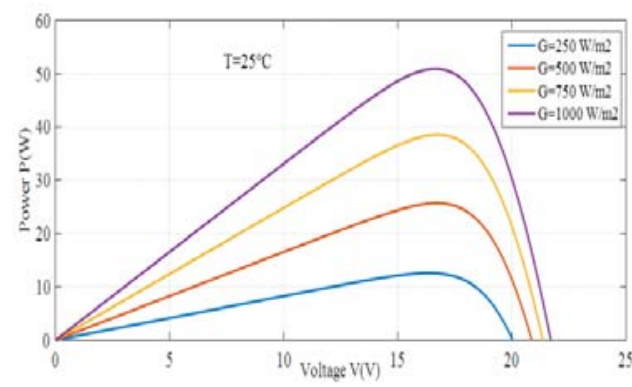

Figure 7. Voltage power characteristic P-V of a photovoltaic module PV for different radiations and constant temperature

\section{Photovoltaic system control by neuron array}

4.1. PV system based on neuron-network

The following figures show the climatic variations measured on the $06 / 01 / 2011$ by the weather services in some Saharan cities of Algeria for a duration of 24 hours Figure 8. Bechar city has been chosen as a sample. Simulation results obtained in 2D and 3D under Matlab/Simulink show the performance of PV system behavior control.

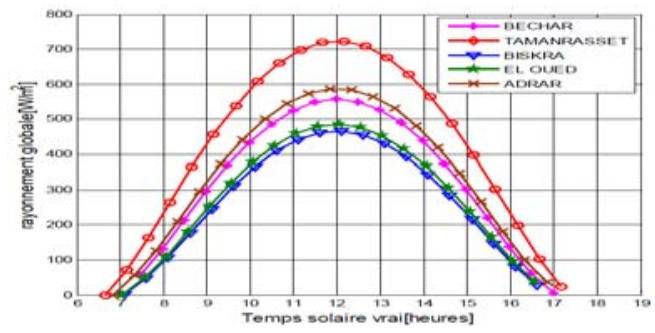

Figure 8. Radiation variation schema for Algerian southern measured by the weather services on 06 January 2011

Int J Pow Elec \& Dri Syst, Vol. 10, No. 3, Sep 2019 : 1575 - 1591 


\subsubsection{Application of ANN on radiation}

The quadratic solar radiation error is very negligible; it is on the order of $10^{-4}$ which explains the importance of ANN as input of the PV panel. Data base radiation variation of Bechar city measured by the weather services on January 06, 2011 over a period of 24 hours without neural network as shown in Figure 9. In Figure 10 is architectural synoptic of radiation proposed by neural network (1-10-1). In Figure 11 is ANN bloc Simulink of radiation. In Figure 12 is ANN training of radiation with Matlab/Simulink. In Figure 13 is the squared error of the ANN training of radiation with Matlab/Simulink.

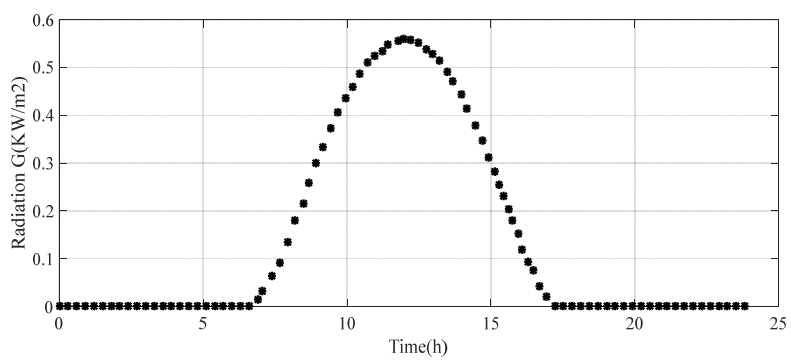

Figure 9. Data base radiation variation of Bechar city measured by the weather services on January 06, 2011 over a period of 24 hours without neural network

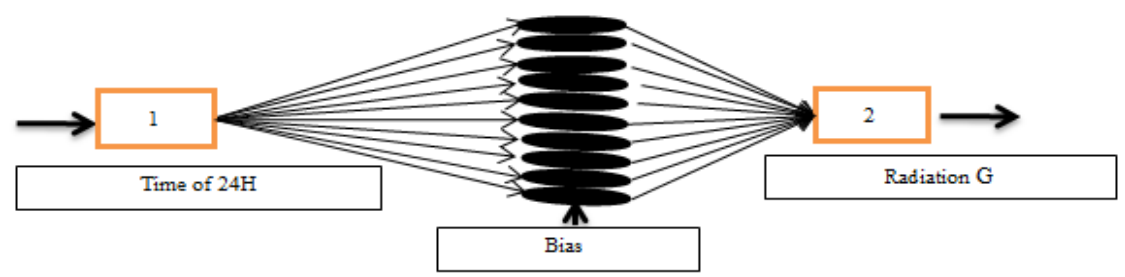

Figure 10. Architectural synoptic of radiation proposed by neural network (1-10-1)

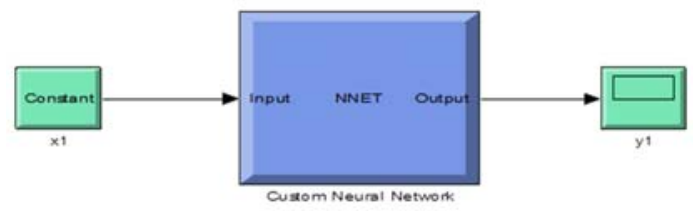

Figure 11. ANN bloc Simulink of radiation

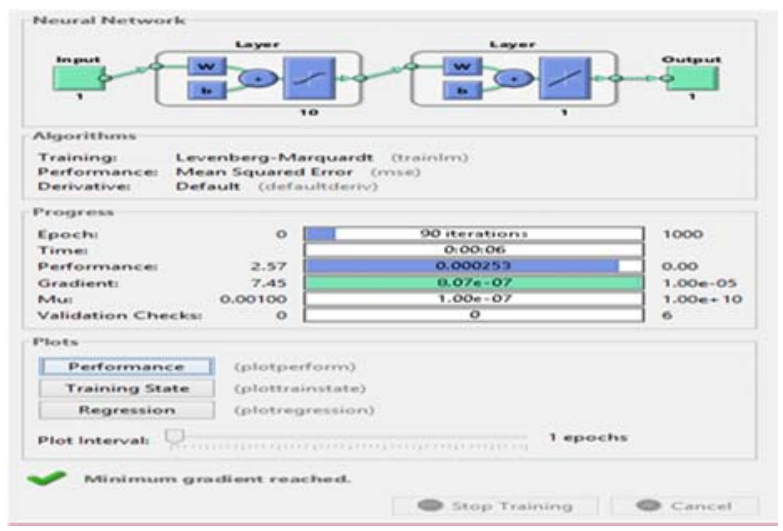

Figure 12. ANN Training of radiation with Matlab/Simulink

Modeling of photovoltaic system with maximum power point tracking control by ... (Farid Saadaoui) 


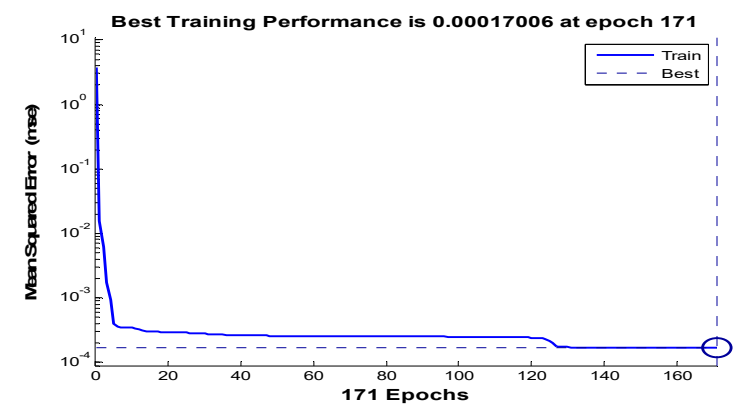

Figure 13. The squared error of the ANN training of radiation with Matlab/Simulink

\subsubsection{Application of ANN on temperature}

Temperature variation schema for Algerian southern measured by the weather services on 06 January 2011 as shown in Figure 14. Data base temperature variation of Bechar city measured by the weather services on January 06, 2011 over a period of 24 hours without neural network as shown in Figure 15. In Figure 16 is architectural synoptic of the proposed neural network of Temperature (1-10-1). In Figure 17 is ANN bloc simulink of temperature as shown.

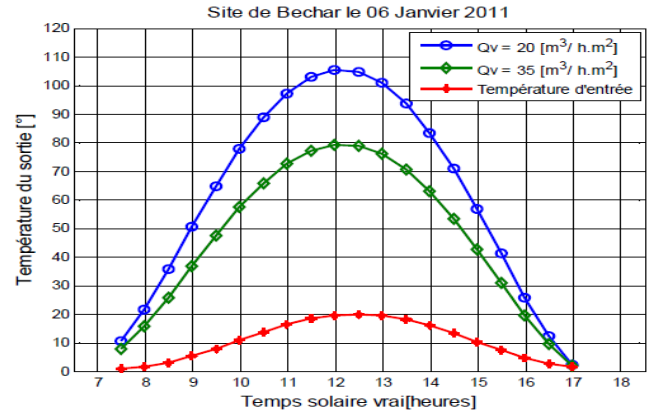

Figure 14. Temperature variation schema for Algerian southern measured by the weather services on 06 January 2011

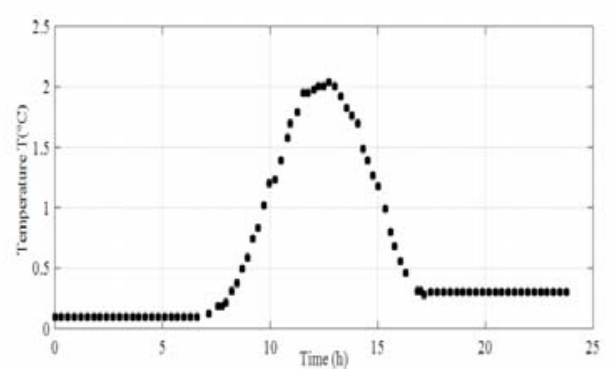

Figure 15. Data base temperature variation of Bechar city measured by the weather services on January 06 ,

2011 over a period of 24 hours without neural network

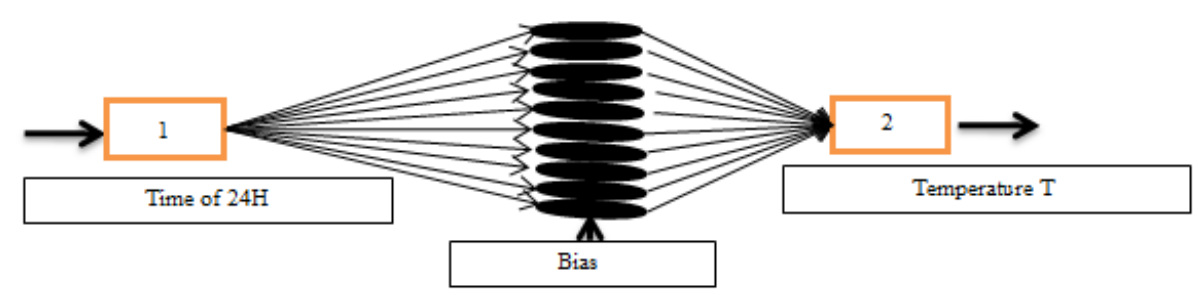

Figure 16. Architectural synoptic of the proposed neural network of temperature (1-10-1) 


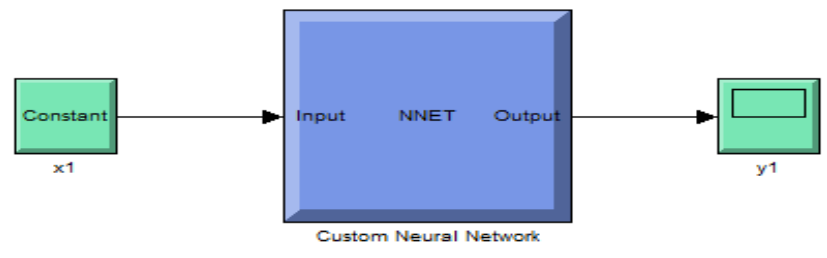

Figure 17. ANN bloc simulink of temperature

We will use two networks of neurons at a time; the first network whose role is to estimate the radiation and the second is to estimate the temperature which give the corresponding current and voltage of the PV panel. In Figure 18 is ANN training of temperature with Matlab/Simulink. In Figure 19 is the squared error of the ANN training of temperature with Matlab/Simulink. In Figure 20 is schema of radiation and temperature variation Bechar city as January 06, 2011 in duration of 24h with neural network
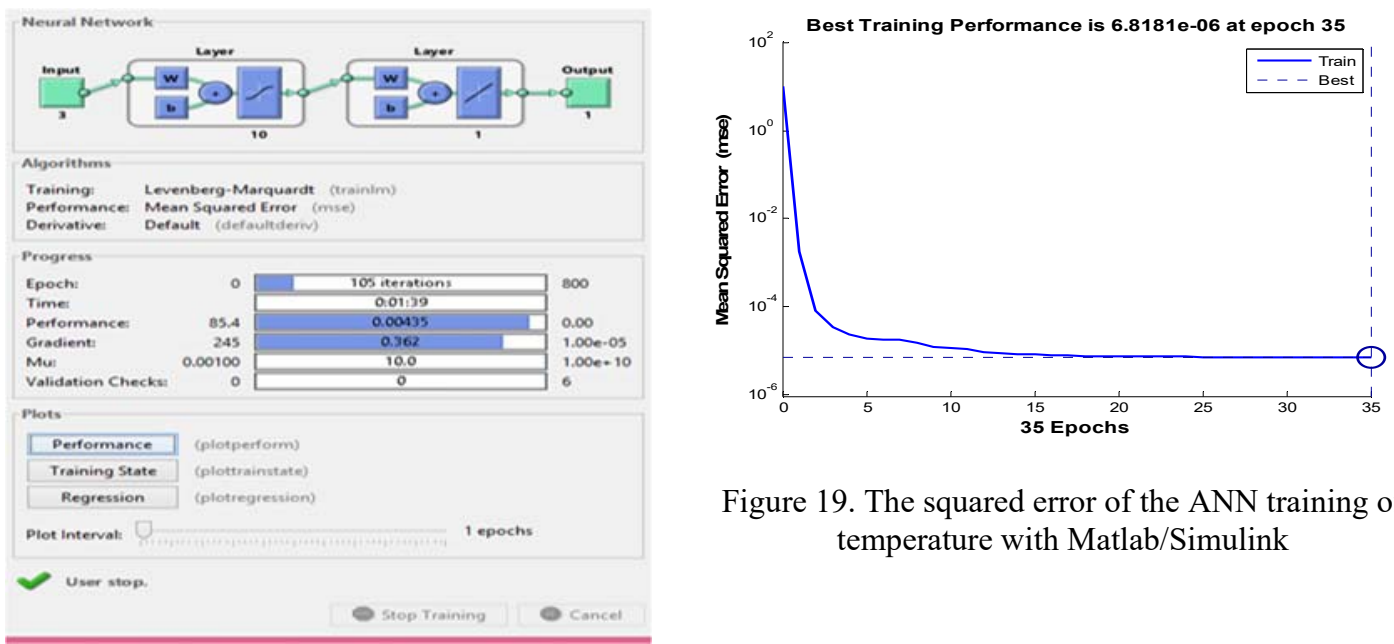

Figure 19. The squared error of the ANN training of temperature with Matlab/Simulink

Figure 18. ANN Training of temperature with Matlab/Simulink

The squared error of the temperature is very negligible, it is on the order of $10^{-4}$ which explains the importance of ANN and the following schema shows the equivalence with Figure 9 and Figure 15.
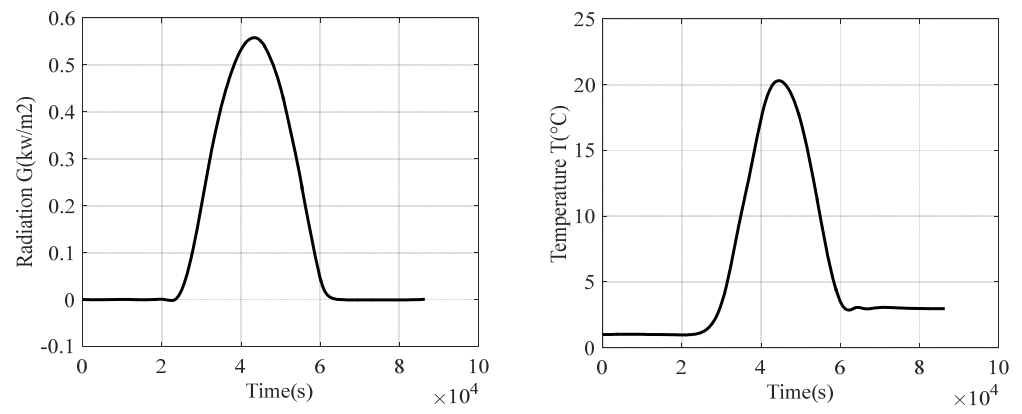

Figure 20. Schema of radiation and temperature variation Bechar city as January 06,2011 in duration of $24 \mathrm{~h}$ with neural network 
The following steps of variations are

- $\quad$ from $00 \mathrm{~h} 00$ to $07 \mathrm{~h} 00$ : the radiation $(\mathrm{G}=0)$ and the temperature $\left(\mathrm{T}=2^{\circ} \mathrm{C}\right)$.

- from $07 \mathrm{~h} 00$ to $12 \mathrm{~h} 00$ : the radiation and the temperature increases rapidly.

- from $12 \mathrm{~h} 00$ to $13 \mathrm{~h} 30$ : the radiation is maximum $(\mathrm{G}=\max )$ and the temperature is also maximum $(\mathrm{T}=\max )$.

- from $13 \mathrm{~h} 30$ to $18 \mathrm{~h} 00$ : the radiation $(\mathrm{G})$ and the temperature $(\mathrm{T})$ begin to decrease rapidly.

- from $18 \mathrm{~h} 00$ to $00 \mathrm{~h} 00$ : at night, no radiation $(\mathrm{G}=0)$ and the temperature tends towards $\left(\mathrm{T}=3.5^{\circ} \mathrm{C}\right)$.

\subsubsection{Application of ANN on the PV generator}

To make the conversion of solar energy into electrical power effective at the output of the PV panel, it is preferable and indispensable to operate it close to a point of maximum power, as this power varies constantly according to the climatological conditions (radiation level solar, temperature of surface and the voltage of module.), or the operating power that is determined from these three inputs directly affects the design and performance of the system.

Current and voltage variation supplied by the PV panel without neural network as shown in Figure 21. In Figure 22 is architectural synoptic of the proposed neural network (3-10-2). In Figure 23 is ANN training of radiation and temperature with Matlab/Simulink. In Figure 24 is the squared error of the ANN training of radiation and temperature with Matlab/Simulink. In Figure 25 is voltage current characteristic, I-V of a photovoltaic module for the different temperatures and constant radiation with neural network. In Figure 26 is voltage power characteristic, P-V of a photovoltaic module for the different temperatures and constant radiation with neural network.
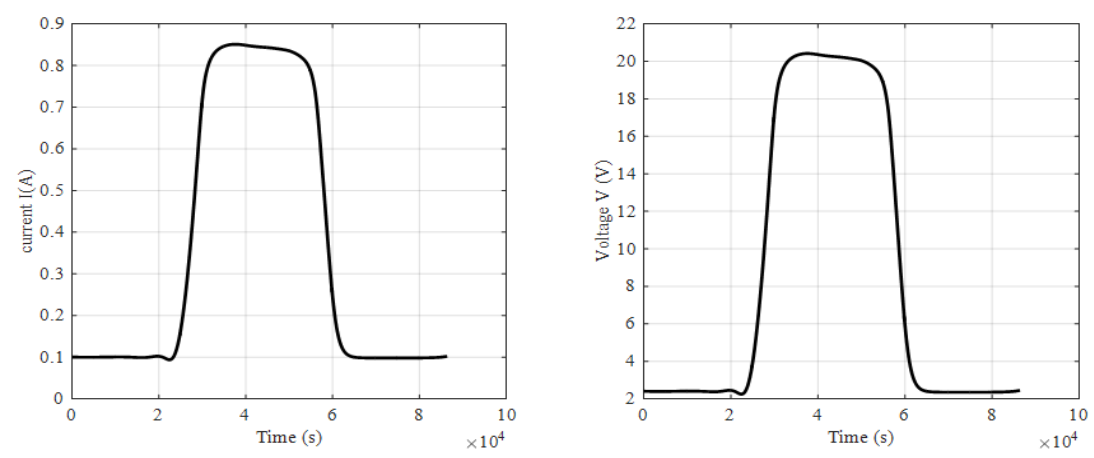

Figure 21. Current and voltage variation supplied by the PV panel without neural network

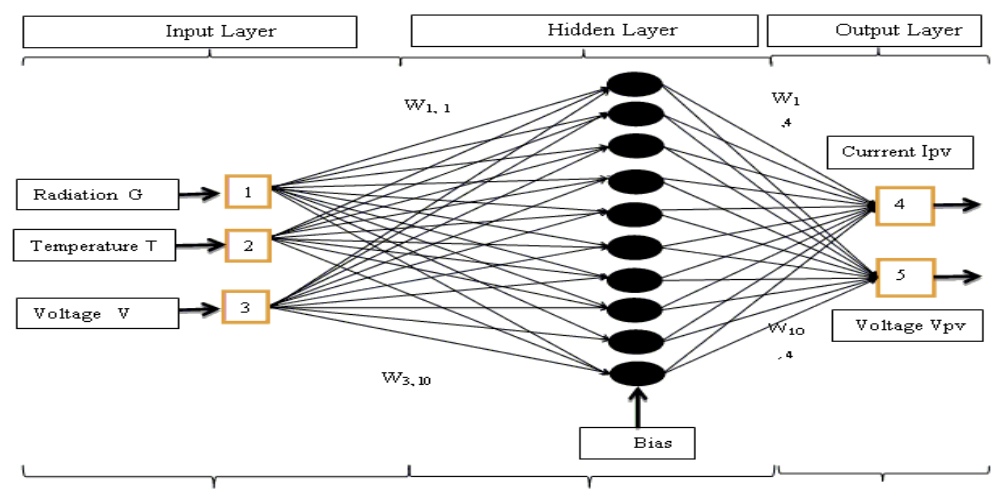

Figure 22. Architectural synoptic of the proposed neural network (3-10-2) 


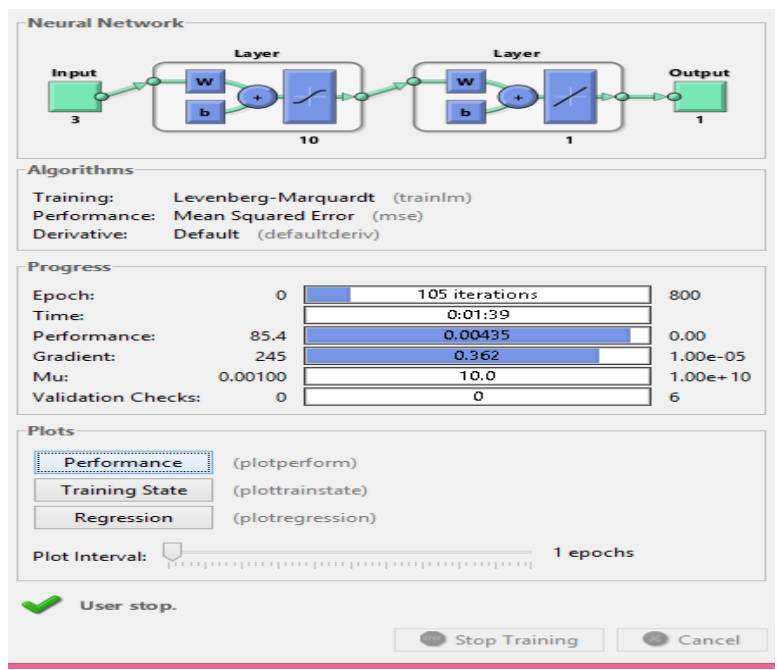

Figure 23. ANN training of radiation and temperature with Matlab/Simulink

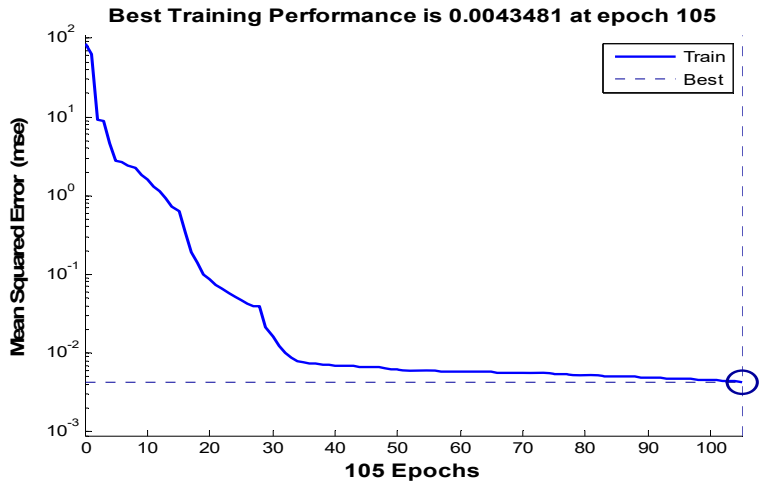

Figure 24. The squared error of the ANN training of radiation and temperature with Matlab/Simulink

The quadratic error is always negligible; it is on the order of $10^{-4}$ which also explains the importance of ANN for the PV panel.

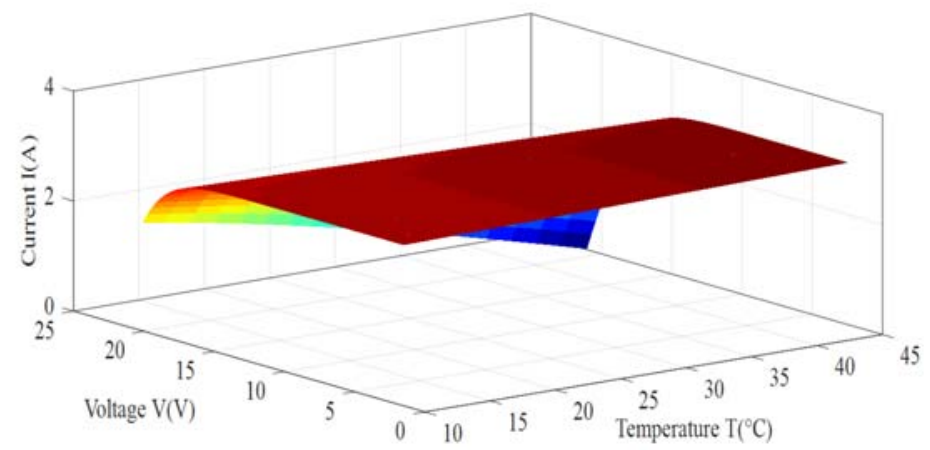

Figure 25. Voltage current characteristic, I-V of a photovoltaic module for the different temperatures and constant radiation with neural network 
The variation of the temperature considering the voltage of Figure 25 with ANN directly influences the PV system and gives the same PV current values as shown in Figure 4, which results in the performance use of the ANN technique for the system.

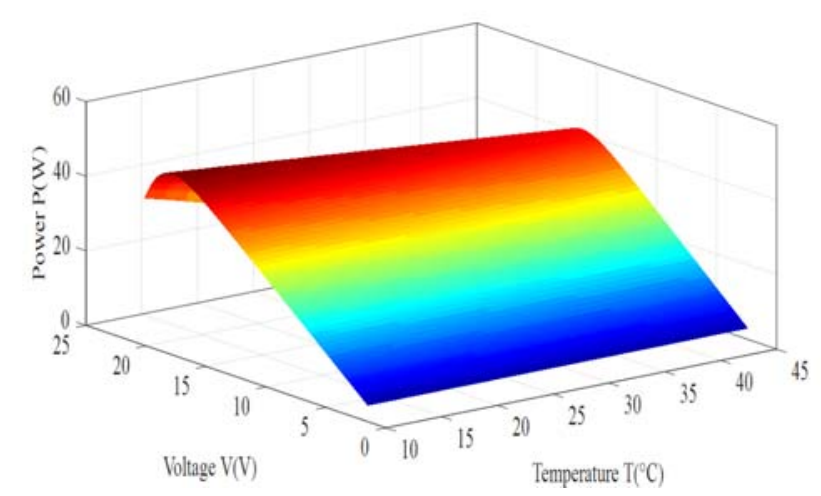

Figure 26. Voltage power characteristic, P-V of a photovoltaic module for the different temperatures and constant radiation with neural network

The variation of the temperature taking into account the voltage of Figure 26, it has a direct influence on the PV system in Figure 5, which results in the use performance of the ANN technique for the system. These figures clearly show the dependence of the current and the output power of the PV as a function of temperature and radiation. For a constant simulation radiation of $1000 \mathrm{~W} / \mathrm{m} 2$ and a temperature which varies from $\left(10^{\circ} \mathrm{C}\right.$ to $\left.45^{\circ} \mathrm{C}\right)$, the maximum current of the PV panel using the neural network is of the same value as Figure 4 between (3.33A and 3.45A). For a variable radiation of $(250 \mathrm{~W} / \mathrm{m} 2$ to $1000 \mathrm{~W} / \mathrm{m} 2)$ and a constant temperature of $25^{\circ} \mathrm{C}$, the current of the PV panel using the neural network is of the same value as Figure 6 between (0.8A to $3.33 \mathrm{~A})$.

In our case where the $\mathrm{G}$ radiation varies between $(0 \mathrm{~W} / \mathrm{m} 2$ to $600 \mathrm{~W} / \mathrm{m} 2)$ winter period of January, the current is between (1.8A to $2.5 \mathrm{~A})$. The results obtained clearly show the advantage of the neuron network given its efficiency, accuracy and speed. The output power provided by the photovoltaic generator is considerably reduced for low radiation. This also shows an effect that might not be immediately obvious and this power is reduced for high panel temperatures. This can be explained by the significant dependence of the temperature on the open circuit voltage Voc.

\subsubsection{ANN application on MPPT controller}

a. Perturbation and observation algorithm

The P\&O method is generally the most used because of its simplicity and ease of implementation for the continuation of the MPPT. Its operation is based on the periodic disturbance of the system by incrementing or decrementing the reference voltage, observing the impact on the power output supplied by the PV panel at instant $(\mathrm{k})$, then comparing it to the previous one at instant (k-1) Figure 27. If the power increases, the MPPT is approached and the change in the BOOST converter (DC/DC) duty cycle $\alpha$ is maintained in the same direction.

On the contrary, if the power decreases, we move away from the MPPT. Then, the direction of the cyclic ratio variation must be reversed and when the maximum power is reached this voltage tends towards the desired voltage. [9], [10] Figure 28.

\section{b. P\&O algorithm based on ANN}

For an application on the PV system, an MPPT controller based on neural networks allowing to produce a cyclic ratio from an input layer included (current, voltage) of the photovoltaic panel Figure 28 . The controller MPPT varies the PV system operating its maximum power by shifting the PV panel voltage to its identified optimum value. The control signal results from the difference between the measured operating power of the PV and the optimal power identified by the ANN [11].

In a period of 24 hours, MPPT control by ANN oscillates the operating point around the MPPT point. In the different cases of change of radiation and temperature of the day of 06/01/2011, it appears that.

Int J Pow Elec \& Dri Syst, Vol. 10, No. 3, Sep 2019 : 1575 - 1591 
During this climate change that lasts from $07 \mathrm{~h}$ to $18 \mathrm{~h}$, the system converges towards the desired MPPT. So the MPPT by ANN command used controls the operation well of the PV generator around the optimal conditions. Figure 29 shows that the controlled current and charge voltage have the same values as those delivered by the PV cell Figure 6, which shows the reliability and importance of the MPPT command by ANN [12].

The right operation of a photovoltaic generator requires MPPT controllers designed to track the maximum power point and thus minimize the error between the operating power and the maximum reference power which varies according to the load and climatic conditions. The system converges to a new current and voltage Figure 28 corresponding to the MPPT.

The PV generator operates at maximum power Pmax when

$$
\begin{gathered}
V p v=V o p t, I p v=I o p t, R s=R o p t=V p v . I o p t \\
P p v=V p v . I p v=P \max =V o p t . I o p t \\
\text { and therefore Pmax }=V \max . I m a x
\end{gathered}
$$

For a given radiation, the optimal operating condition of the PV generators is then characterized by a voltage Vopt and a current Iopt. The Vopt product per Iopt thus constitutes the maximum power that can be extracted from the PV module. This point Vopt and Iopt is called the maximum power point of the PV generator for a given temperature and radiation. It is characterized by an optimal internal resistance Ropt of the generator [12].

The modelling of the PV system by the ANN can be seen as a step towards a rapprochement between precise mathematical pursuit and human decision-making. The neural chaser has proven that it has better performance with negligible errors and is robust to different atmospheric variations. Also, these results confirm a better functioning of the neural pursuer compared to the traditional pursuer P \& O [13-14].

A recent utilization of the ANN in the PV energy sector elaborates, which is maximum power forecasting. Although the main concern of this article is to present a survey on ANN-based PV MPPT techniques, the authors prefer to give a preview of this research field leaving further investigation to interested readers [15-16].

In solar PV system, tracking the module's MPP is challenging due to varying climatic conditions. Moreover, the tracking algorithm becomes more complicated under the condition of partial shading due to the presence of multiple peaks in the power voltage characteristics [17-18]. The ANN is trained for various conditions of solar radiation and temperature to estimate the MPP voltage. This voltage is then used by ANN as a reference voltage to generate the appropriate control signal for the DC-DC converter [19].

Recent researches oriented to photovoltaic systems feature booming interest in current decade. For efficiency improvement, maximum power point tracking of PV array output power is mandatory. Although classical MPPT techniques offer simplified structure and implementation, their performance is degraded when compared with artificial intelligence-based techniques especially during partial shading and rapidly changing environmental conditions. Artificial neural network algorithms feature several capabilities such as: off-line training, nonlinear mapping, high-speed response, robust operation, less computational effort and compact solution for multiple-variable problems. Hence, ANN algorithms have been widely applied as PV MPPT techniques. Among various available ANN-based PV MPPT techniques, very limited references gather those techniques as a survey. Neither classification nor comparisons between those competitors exist. Moreover, no detailed analysis of the system performance under those techniques has been previously discussed [20-21].

The output power of PV systems varies with the intensity of the solar irradiance and the environmental temperature. Due to the nonlinear current-voltage (I-V) characteristics of the solar cell, there is a unique maximum power point (MPP) on the power-voltage $(\mathrm{P}-\mathrm{V})$ curve. Global maximum power point tracking is one of the basic measures to improve the overall efficiency of the PV power generation systems. However, real environments experience partial shading, which is a condition whereby a portion of the PV module (or array) is shaded, while the other parts remain uniformly irradiated. When a PV array is subjected to partial shading, a considerable amount of energy is lost because the shaded module is short-circuited by its bypass diode. This forces its voltage, and consequently power, to be reduced to zero and the $\mathrm{P}-\mathrm{V}$ curve exhibits a complex multi-peak shape. In this case, the traditional algorithms using gradient information, such as the perturb-and-observe (P \& O) and incremental conductance (INC) algorithms, become invalid [22]. 


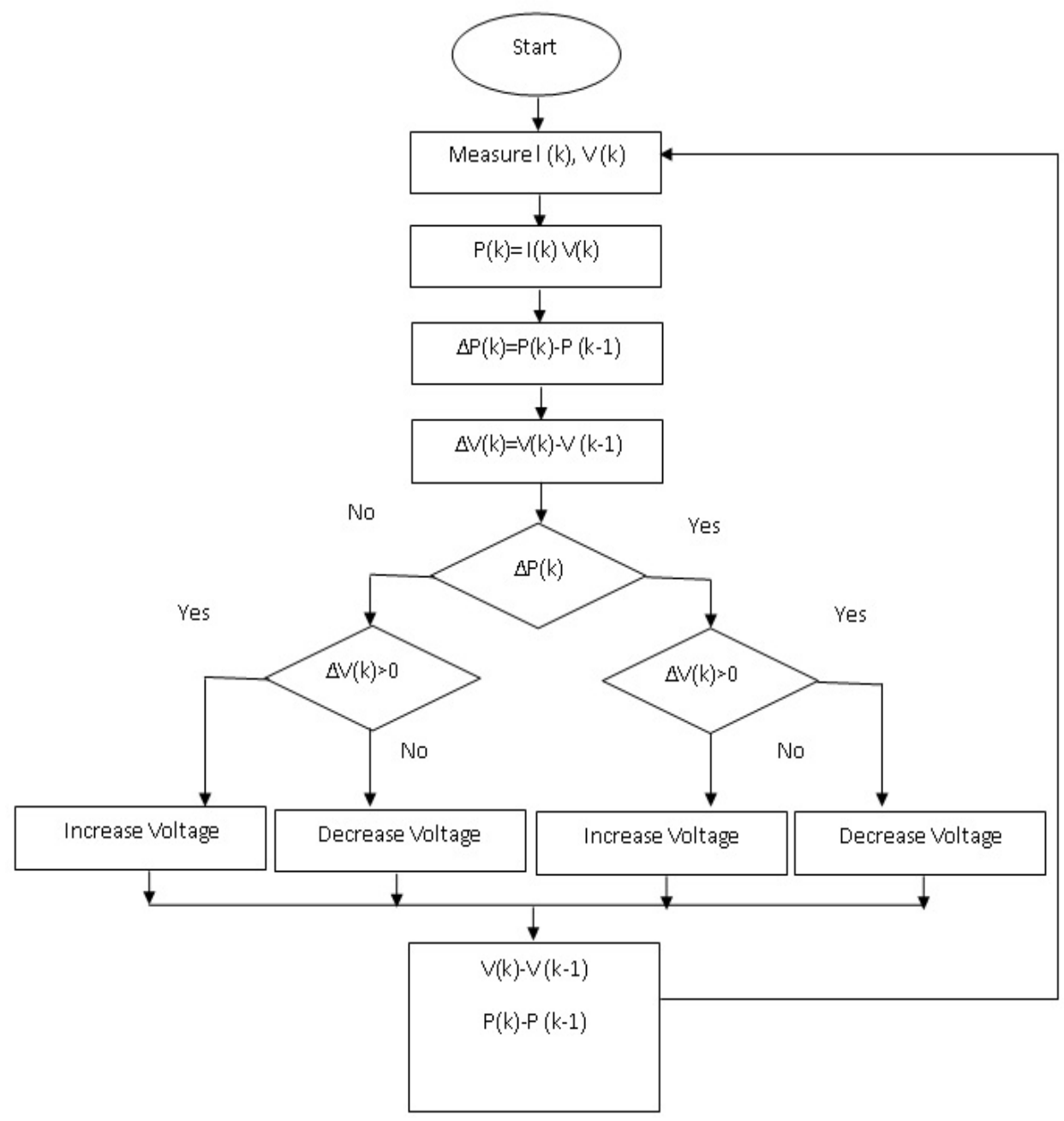

Figure 27. Perturbation \& Observation MPPT algorithm

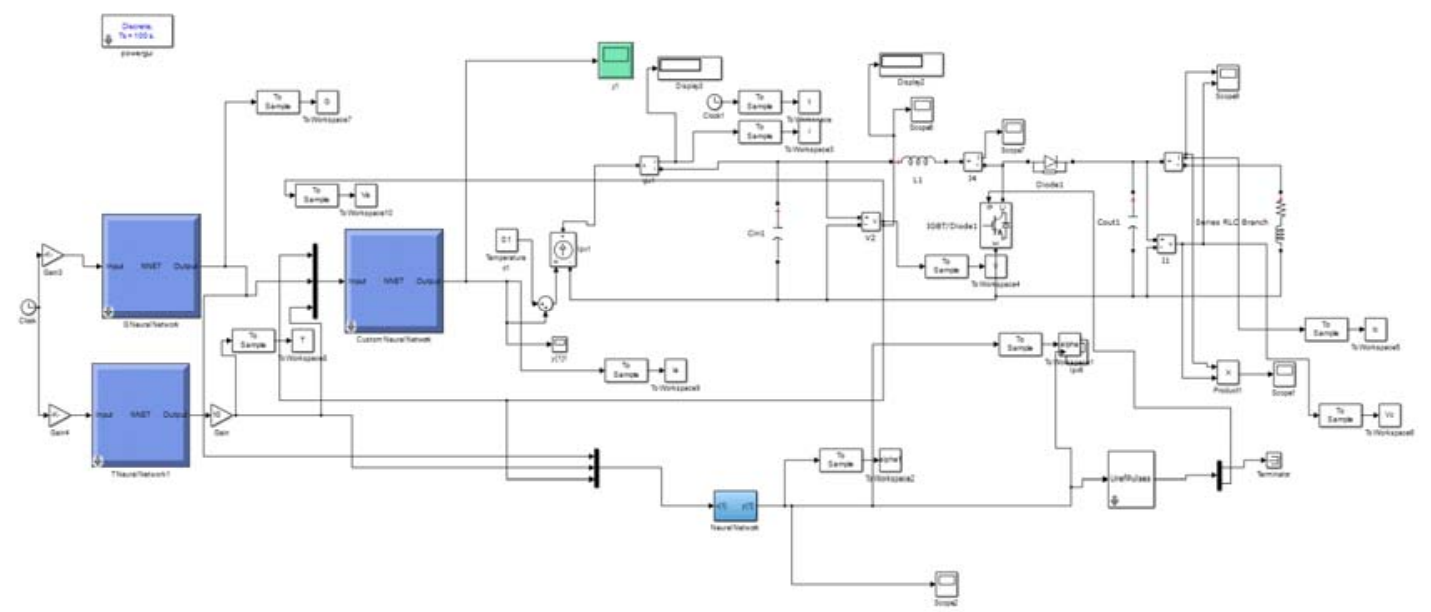

Figure 28. Simulation model of photovoltaic system by the MPPT technique with ANN 


\section{RESULTS AND AND DISCUSSIONS}

The study of the MPPT technique based on ANN generalized to the PV system (radiation and temperature of the module, the PV module and the MPPT command) illustrates the simplicity of its implementation. Therefore, this section is intended to give the reader a discussion and a comparison of the results compared to the conventional P \& O MPPT method.

The ANN generates a reference voltage which is compared to the instantaneous output voltage of the panel to generate an error signal. This error signal is sent to a PI controller for adjustment of duty cycle for MPP tracking. Performance is evaluated in terms of response time and efficiency monitoring.

DC-DC converters are used to transfer power of solar panel to load side ensuring that maximum power has been transferred. The regulation is normally achieved by pulse within modulation and the switching device is normally MOSFET or IGBT. Boost DC-DC converter's function is to step up DC voltage. Figure 28 shows configuration of DC-DC Boost converter with PV as input. Maximum power is reached when the MPPT algorithm changes and adjusts the duty cycle of the Boost DC-DC converter [23-24]. In Figure 29 is DC load current and voltage variation with MPPT control with ANN.
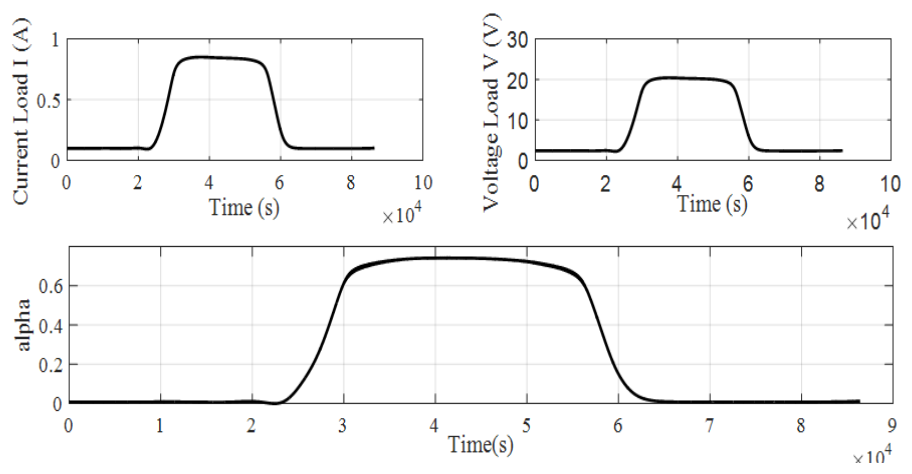

Figure 29. DC load current and voltage variation with MPPT control with ANN

The ANN is trained to determine the global MPP voltage under several partially shaded conditions [24]. This step makes it possible to verify that the three networks neural after learning is actually able to predict the desired output for input data values that are not used during learning. We must always compare the true output of the trajectory of neural networks with the trajectory of the model of photovoltaic cells, which is still our reference for any comparison [25].

Use of ANN in MPPT has proven to be very efficient due to its high accuracy. But the only problem an ANN based tracker faces is that it needs a big database for prediction of the reference voltage signals and for different systems, unique neural networks are required to be trained. Hence long term testing is essential before ANN implementation in a system [26].

There is a lot of research going on in the field of MPP techniques. It is very important to decline that our manuscript has a very important and not insignificant value given the advantage of ANN for the good exploitation of a photovoltaic installation in the energy field and that it will add a line of research to the listed MPP techniques.

\section{CONCLUSION}

The general public's interest in renewable energies continues to grow. Among the various renewable energy sources, photovoltaic occupies a prominent place. The use of artificial intelligence technology is appropriate to optimize a photovoltaic system based on neural networks in order to obtain maximum operating power under different climatic conditions. To make the conversion of solar energy into electrical power output of this system efficient, it is preferable and essential to operate it close to a maximum power point since this power constantly varies according to solar irradiation, temperature and voltage or charging current, i. e, these three inputs directly influence the design and performance of a photovoltaic panel system.

Neural networks with their ability to adapt to complicated problems through learning, are today a real tool for solving several cases where conventional methods have shown their limits. In particular, the pursuit of the maximum power point by the ANN approach for the implementation of energy systems has attracted a big attention to offer better accurate calculation solutions with better response time and good

Modeling of photovoltaic system with maximum power point tracking control by ... (Farid Saadaoui) 
performance. Also, a very good agreement is obtained between the model of photovoltaic cells and neural approach. Given its robustness and efficiency, the use of ANN methods has allowed an automatic generation of artificial intelligence rules and the precision of its outputs allow it to give firm and precise decisions, able to avoid inconsistent cases in order to achieve an efficient system.

\section{REFERENCES}

[1] M. R Sourov, U. Tania Ahmed, M. Golam Rabbani, "A High Performance Maximum Power Point Tracker for Photovoltaic Power System Using DC-DC Boost Converter," IOSR Journal of Engineerin,. 2(12): 12-20, 2012.

[2] N. Kishor, S. R. Mohanty, M. G. Villalva and E. Ruppert, "Simulation of PV Array Output power for Modified PV Cell Model," IEEE, International Conference on Power and Energy (PEC), Kuala Lumpur, Malysia, 2010.

[3] J. S. Kumari, Dr. Ch. Sai Babu and A. Kamalakar Babu, "Design and Analysis of P\&O and IP\&O MPPT Techniques for Photovoltaic System," International Journal of Modern Engineering Research ( IJMER), 2(4): 2174-2180, 2012.

[4] Gh. Remy, O. Bethoux, C. Marchand, and H. Dogan. Review of MPPT Techniques for Photovoltaic Systems. Laboratoire de Génie Electrique de Paris (LGEP)/SPEE-Labs, CNRS UMR 8507, SUPELEC; Université Pierre et Marie Curie P6; Université Paris-Sud 11, rue Joliot Curie, Plateau de Moulon F91192 Gif sur Yvette CEDEX; France : pp. 1-14.

[5] M. Amoozadeh and S. A. Gholamian, "Active and Reactive Power Control of Photovoltaic Systems Connected to the Network for Maximum Power Point Tracking," International Journal of Mechatronics, Electrical and Computer Technology (IJMEC), 4(12): 857-885, 2014.

[6] K. Mammar, A. Chacker. Adaptive Neuro-fuzzy Controller of PEM fuel cell System Power Generation. International Journal of Computer Science (IJCSI). 2012; 9(6): 1694-081.

[7] T. T. Guingane, Z. Koalaga, E. Simonguy, F. Zougmore, D. Bonkoungou, "Modélisation et simulation d'un champ photovoltaïque utilisant un convertisseur élévateur de tension (boost) avec le logiciel MATLAB/SIMULINK," Journal International de Technologie, de l'Innovation, de la Physique, de l'Energie et de l'Environnement JITIPEE, 2(1): 1-14, 2016.

[8] N. Aouchiche, M.S. Aï Cheikh et A. Malek, "Poursuite du point de puissance maximale d'un système photovoltaïque par les méthodes de l'incrémentation de conductance et la perturbation \& observation," Revue des Energies Renouvelables. 16(3) : 485-498, 2013.

[9] M. Rebhi, A. Benatiallah, M. Sellam, "Etude technico-économique d'un système hybride photovoltaïque-diesel en milieu saharien," Thèse de Doctorat, Département des sciences de la matière, Faculté des sciences exactes, Université Tahri Mohammed Béchar, Algérie, soutenue 2017.

[10] P. Kinjal, K B. Shah and G R. Patel, "A Maximum Power Point Tracking Method Based on Perturb \& Observe Algorithm of PV System," Indian Journal of Applied Research, 5(1): 17-20, 2015.

[11] D. Mathur. Maximum Power Point Tracking with Artificial Neural Network. International Journal of Emerging Science and Engineering' IJESE). 2014; 2(3): ISSN: 2319-6378.

[12] A. Elgharbi, D. Mezghani, A. Mami, "A Maximmum Power Point Tracking Method Based On Artificial Neural Network For a PV System,” International Journal of Advances in Engineering \& Technology (IJAET), 5(1): pp. 130-140, 2012.

[13] B. Bendib, F. Krim, H. Belmili. T, M. F. Almi, "Modélisation et Commande MPPT d'un système photovoltaïque autonome en utilisant les réseaux de neurones artificiels," Le 2ème Séminaire International sur les Energies Nouvelles et Renouvelables Unité de Recherche Appliquée en Energies Renouvelables. Ghardaïa-Algérie. 2012: 1-6.

[14] D. Ganesh, S. Moorthi, H. Sudheer, "A Voltage Controller in photovoltaic System with Battery Storage for Stand-Alone Applications," International Journal of Power Electronics and Drive System (IJPEDS), 2(1): 9-18, 2012.

[15] L.M. Elobaid, A.K. Abdelsalam, E. E. Zakzouk, "Artificial neural network based maximum power point tracking technique for PV systems," $38^{\text {th }}$ Annual Conference on IEEE Industrial Electronics Society, IECON 937-942, 2012.

[16] L. M. Elobaid, A. K. Abdelsalam, E. E. Zakzouk, "Artificial neural network-based photovoltaic maximum power point tracking techniques: a survey," IET Renewable Power Generation, 9(8): 1043-1063, 2015.

[17] K. Punitha, D. Devaraj, S. Sakthivel, "Artificial neural network based modified incremental conductance algorithm for maximum power point tracking in photovoltaic system under partial shading conditions," International Journal of Energy, 62: 330-40, 2013.

[18] M. D Singh, V. J. Shine, V. Janamala, "Application of artificial neural networks in optimizing MPPT control for standalone solar PV system," Int. Conf. on Contemporary Computing and Informatics (IC3I), 162-166, 2014.

[19] B. Bendib, F. Krim, H. Belmili, M. F. Almi, S. Bolouma, "An intelligent MPPT approach based on neural-network voltage estimator and fuzzy controller, applied to a stand-alone PV system,” IEEE 23rd Int. Symp. on Industrial Electronics (ISIE). Istumbul, Turkey. 404-409, 2014.

[20] M. Slimi, A. Boucheta, B. Bouchiba, "Maximum power control for photovoltaic system using intelligent strategies," International Journal of Power Electronics and Drive System (IJPEDS), 10(1): 423-432, 2019.

Int J Pow Elec \& Dri Syst, Vol. 10, No. 3, Sep 2019 : 1575 - 1591 
[21] M. Manas, A. Kumari, S. Das, and all, "An Artificial Neural Network based Maximum Power Point Tracking method for photovoltaic system," IEEE International Conference on Recent Advances and Innovations in Engineering (ICRAIE), Jaipur, ISSN: 5090-2806, India 2016.

[22] M. Chen, S. Ma, J. Wu and L. Huang, "Analysis of MPPT Failure and Development of an Augmented Nonlinear Controller for MPPT of Photovoltaic Systems under Partial Shading Conditions," Journal applied sciences (MDPI), 7(95): 1-22, 2017.

[23] N. Khaldi, H. Mahmoudi, M. Zazi, Y. Barradi, "Implementation of a MPPT Neural Controller for PhotovoltaicSystems on FPGA Circuit,” TRANSACTIONS on POWER SYSTEMS (WSEAS), 9 : 471-478, 2014.

[24] L. Bouselhama, M. Hajjia, B. Hajji, H. Boualia, "A new MPPT-based ANN for photovoltaic system under partial shading conditions," 8th International Conference on Sustainability in Energy and Buildings, Energy Procedia. Turin, ITALY, 111: 924 - 933, 2017.

[25] M. Hadjab, A. Benzina, A. Djellid, S. Berrah, H. Abid. L'intelligence artificielle pour la poursuite du point de puissance maximum d'un générateur photovoltaïque. Séminaire sur l’Energie, 1-6, Alger 25-27 Mar 2012.

[26] J. Mahanta, B. Sharma, N. Sarmah, "A Review of Maximum Power Point Tracking Algorithm for Solar Photovoltaic Applications," Journal of Electrical and Electronics Engineering (IOSR-JEEE), 13(4): 01-13, 2018. 